\title{
Replacement of Potassium by Rubidium in Nitzschia closterium.
}

\author{
By
}

\section{F. A. Stanbury, M.Sc.}

With 2 Figures in the Text.

VARIOUS attempts have been made to substitute certain elements for those acknowledged as essential for plant growth. Using plant material, sodium is the element usually chosen as a possible substitute for potassium, but results show that whilst sodium may be taken up in fairly considerable quantities this is only possible if small amounts of potassium be present as well. Total replacement appears to be impossible $(11,13,15)$.

The failure to substitute sodium is not really surprising, for although there is considerable likeness, there are important differences between the two elements. A substance more nearly approaching potassium is the element rubidium. Rubidium can only with great difficulty be distinguished chemically from potassium. Apart from the differences of their absorption spectra-differences which are not altogether reliable when dealing with very small amounts of these elements or when in the presence of other substances (10) - the only means of clearly distinguishing between them appears to lie in the differences between the properties of such complex substances as their meta-stannates or the tetra-thio carbamides of their respective iodides $(\mathbf{1 0 , 5}$, and $\mathbf{6})$.

The possible substitution of rubidium was tried by Cameron (8) with remarkable success. He used plants of Petroselinium sativum grown from seeds in an artificial soil of alumina and charcoal. The alumina was stated to be free from potassium, as was the charcoal, which was obtained by the imperfect combustion of sugar, both substances having been tested spectroscopically. This artificial soil was contained in a vessel of block tin and "manured" with nutritive material containing no potassium. The seedlings were watered with a solution containing rubidium chloride. Plants producing seeds resulted from these experiments. Compared with normal control plants, the "culture" plants were not so robust, but the fact remains that a cultivated plant, in which potassium occurs in a very large proportion in the ordinary way, was grown to a state of maturity on soil free from this element. Other plants grown upon the same type of artificial medium and under identical conditions except that they were not 
watered with the rubidium chloride solution, very quickly died, so that it would seem that the rubidium really replaced the potassium, but as Cameron himself pointed out, it is very difficult to obtain exact results when using any of the higher plants. The seeds from which the plants were grown would contain a certain amount of potassium, and this amount, although small, might be sufficient to influence growth throughout life. In testing the ash of the matured "culture " plant Cameron reported that " minute traces" of potassium were present, and he considered that this had been derived from the seed from which the plant had been grown. To obtain really conclusive results the seeds of the "culture" plant should have been grown for a number of successive generations, for only thus would it seem possible to reduce the potassium present in the final plants to a minimum approaching elimination.

Using rubidium sulphate an attempt to replace potassium has now been made using the marine diatom Nitzschia closterium as the plant material. In this diatom, growth is relatively rapid, so that the products of several successive generations can be obtained in a comparatively short time. It could, therefore, be hoped to obtain by sub-culturing from normal parent stock, diatoms from which the element potassium was gradually eliminated.

The results of such experiments are presented in the following pages.

\section{Material Used and Method of Working.}

The stock material was that of a persistent culture of Nitzschia closterium, a marine diatom grown in sterilized natural sea-water to which nutritive material had been added in the form of "Miquel solution " (1\%). Artificial sea-water was made up according to the method described by Allen (1). All the elements of natural sea-water, excepting potassium, were present in their proper proportions. Nutrient material was added in the form of a modified "Miquel solution," the potassium salt again being omitted and substituted by one of sodium. The salts used were Kaulbaum salts, pure for analyses, or of the British Drug House-analytical quality : the water used was freshly distilled into Winchester quart bottles which had once contained strong acid, but which had been used for distilled water only for at least five years. All the ingredients were dissolved and kept in quartz vessels to prevent any possible contamination with potassium. The artificial medium gave no flame test for potassium with either the ordinary blue or with the didymium glass-a glass which transmits the blue freely whilst completely blocking the wave lengths emitted by sodium. The absence of potassium was also verified spectroscopically by a technique which was capable of detecting $2 \times 10^{-5} \mathrm{mg}$. potassium per cubic millimetre, but failed to detect half of this amount. 
This potassium-free (-K) artificial sea-water was sterilized, and 80 cubic centimetres of it were poured into a clear quartz flask and inoculated with a very small drop of Nitzschia culture containing a known number of diatoms per unit of volume. This sub-culture (A) was then covered with a quartz plate and kept sufficiently aerated, and placed in a window receiving light of a suitable intensity for diatom growth. The aeration of the sub-culture was effected by a sterilized pipette, which after sterilization had been rinsed in the sterilized potassium-free sea-water described. The counting of the diatoms was done with a hœmocytometer (1\%). In every case five counts were made and the figure recorded is the mean of five counts which were usually quite concordant.

A trace of potassium was naturally introduced with the inoculating drop. This, together with any traces of potassium present in the artificial medium, but not detectable by the spectroscopic method, was soon used up, as was indicated by the results of counting, since a point was reached where no further increase in numbers occurred. Table I. It was therefore assumed that the sub-culture A was now devoid of any available potassium. No further increase in numbers was recorded although the diatoms present appeared quite healthy, but a little smaller in size than the normal.

Using a new supply of potassium-free sea-water, a new sub-culture (B) was made from the potassium-depleted culture $A$. There was very little multiplication in the new sub-culture B as may be seen from Table II.

\section{TABLE I.}

To show the Growth of Sub-culture A of Nitzschia closterium transferred from Normal Sea-water to a Potassium-free Artificial Medium.

Date. No. of diatoms per unit of volume, viz. $0.1 \mathrm{~mm}^{3}$.

$\begin{array}{rrrrrr}12.6 .32 & . & . & . & . & 14 \\ 15.6 .32 & . & . & . & . & 58 \\ 19.6 .32 & . & . & . & . & 69 \\ 26.6 .32 & . & . & . & . & 85 \\ 3.7 .32 & . & . & . & . & 78 \\ 8.7 .32 & . & . & . & . & 94 \\ 13.7 .32 & . & . & . & . & 94 \\ 13.9 .32 & . & . & . & . & 94\end{array}$

The spectroscopic test showed the medium to be free from potassium, although this test is really valueless at this stage, since growth did take place in the potassium-free medium in spite of its failing to show any trace of potassium by this test. At this point the sub-culture B showed 
$6 \times 10^{4}$ diatoms per cubic centimetre of solution, and the figure remained constant for a period of several weeks.

Sub-culture B was then shaken very thoroughly to ensure equal distribution of the diatoms throughout the medium, and divided into seven equal portions, each being poured into a small quartz crucible of ten cubic centimetres capacity. To six of the divided cultures known amounts

\section{TABLE II.}

To show the Growth of Sub-culture B of Nitzschia closterium transferred from the Potassium-depleted Sub-culture A, to fresh Potassium-free Artificlal Medium.

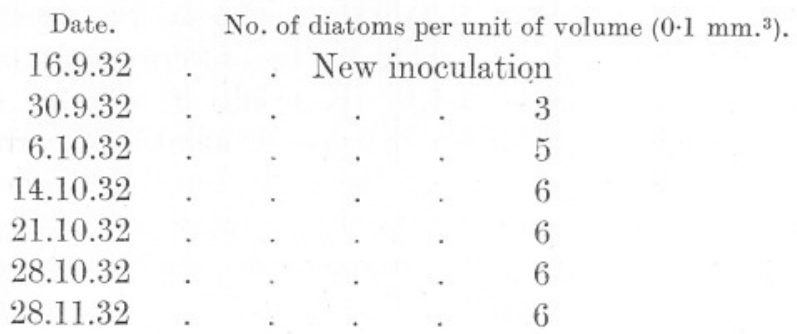

of potassium or rubidium were then added, numbers 1,2 , and 3 receiving potassium as potassium sulphate and 4,5 and 6 receiving rubidium as rubidium sulphate. Crucible 7 was left untouched (see Table III). The crucibles were then covered with quartz glass plates and set aside in the window, and aerated and counted in the usual way. The drops taken for counting were always rejected after use. The "la," " $2 \mathrm{a}$ " etc. crucibles refer to a second series done later.

\section{Results.}

Two series of experiments were performed. The first series during the Winter and early Spring, November 28th-March 3rd, and the second during the Autumn, September 25th-November 24th.

Previous work with Nitzschia closterium has shown that the growth figures at any time of the year show peculiar rising and fallings, the cause of which cannot satisfactorily be explained (17). The cultures at present under consideration also show these irregularities (see Tables III and IV). With the exception of the untouched cultures 7 and $7 \mathrm{a}$, all show increase in growth. In the first series of experiments, the increase is fairly steady for a period of fifty-one days, and towards the end of this time the figures tend to be proportional to the amount of potassium added in cultures 1,2 , and 3 . The same tendency is shown in the potassium containing 
cultures of the second series. The extraordinary growth of culture 2, which received $10 \gamma \mathrm{K}$ per c.c. of culture solution, can only be explained on the supposition that some impurity had inadvertently been admitted whilst extracting droplets for counting. Increase in temperature and in the length of the day as the year had proceeded could not alone account for such growth (Figs. 1 and 2.)

The continued fall in numbers in culture 3, after a very short growth

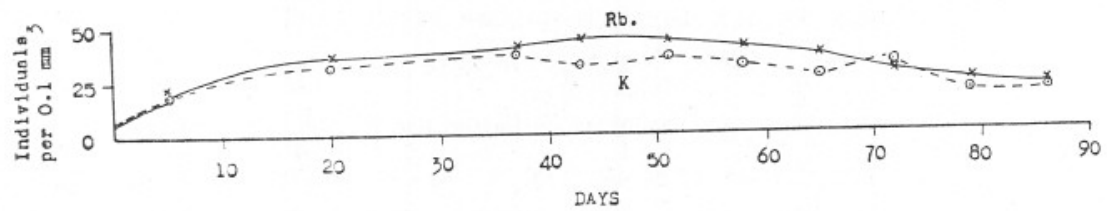

FIG. 1 .

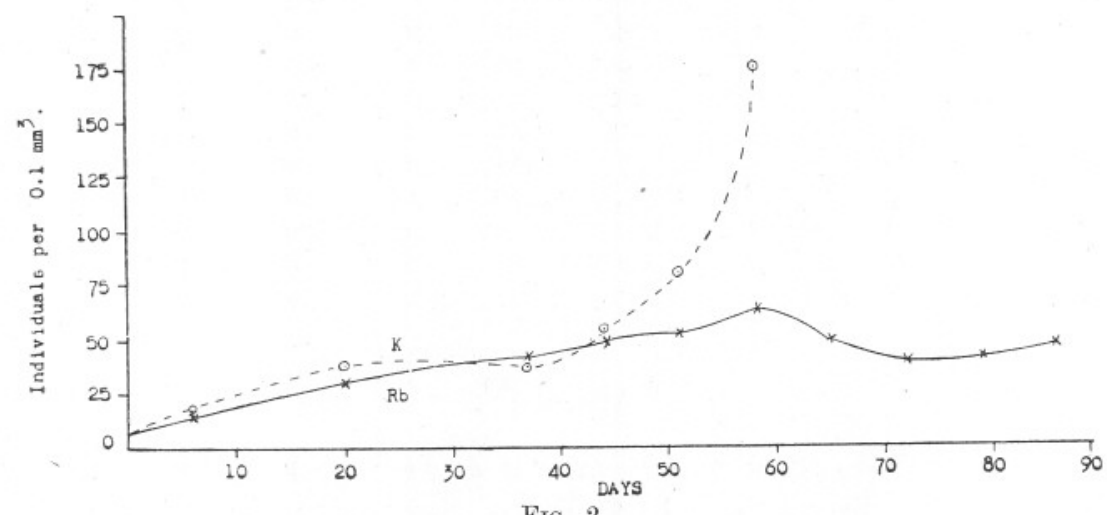

FIG. 2.

FIGS. 1 and 2.- Showing growth of Nitzschia closterium in artificial sea-water containing known amounts of potassium or rubidium respectively-viz. 4 micrograms of $\mathrm{K}$. or Rb. in Fig. 1, and 10 micrograms of K. or Rb. in Fig. 2.*

period, is probably due to potassium starvation, and it would seem that the limiting value of potassium-requirement is being reached-viz. $4 \gamma \mathrm{K}$ per c.c. of culture. The diatoms were small and in an unhealthy condition. A similar amount of rubidium in culture 6 gave slightly better growth throughout the course of the first series of experiments, and although the diatoms were small in size they appeared quite normal and healthy in form when seen under the microscope. Culture 4 shows the poorest growth, although it contains the largest proportion of rubidium, viz. $21 \gamma \mathrm{Rb}$. per c.c. of culture solution. This amount appears to be injurious for continued growth. It therefore seems that, although rubidium may be harmful in certain proportions (culture 4), in smaller

* In Fig. 2 the "potassium" curve shows abnormal growth after 51 days. This is probably due to some trace of impurity, possibly introduced during aeration of the cultures. 
amounts (culture 6) it is quite as efficient as similar amounts of potassium, but even in that case increase is restricted to $7-11$ times their original number.

\section{TABLE III.}

To show the Growth of the Sub-cultures of Nitzschia Closterium when supplied with known Amounts of Potassium or Rubidium RESPECTIVELY SHOWN as Micrograms PER C.C. $\left(10^{-6} \mathrm{~g}=\gamma\right)$, OVER A Period of 86 Days. Nov. 28th-March 3RD (1932-1933)

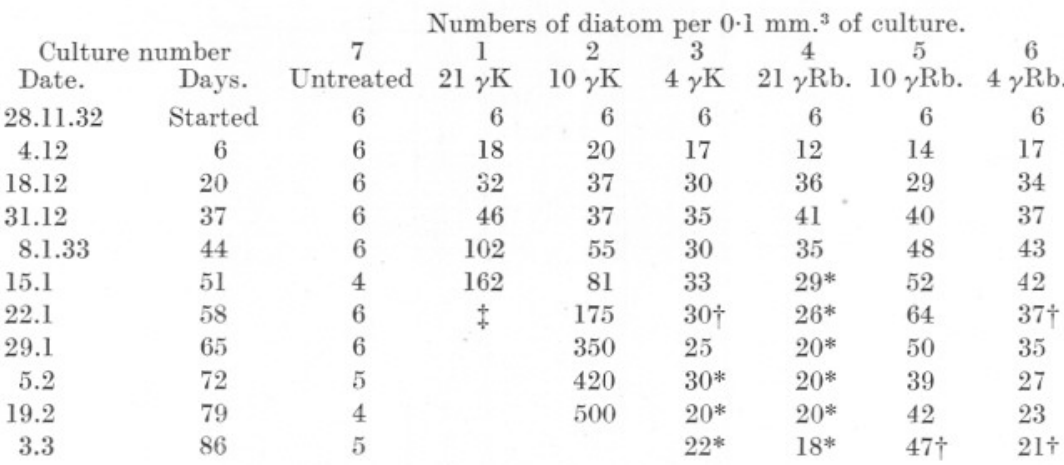

\section{TABLE IV.}

Amount of Potassium and Rubldium as above. Experiment conducted over a Period of 69 Days. Sept. 25th-Nov. 24th, 1933.

$\begin{array}{ccrrrrrrr}1933 . & \text { Days. } & \text { 7a. } & \text { la. } & \text { 2a. } & 3 \text { a. } & 4 \text { a. } & 5 \text { a. } & 6 \text { a. } \\ 25.9 .33 & \text { Started. } & 6 & 6 & 6 & 6 & 6 & 6 & 6 \\ 6.10 & 11 & 6 & 18 & 14 & 13 & 15 & 12 & 12 \\ 13.10 & 18 & 6 & 32 & 29 & 23 & 22 & 32 & 21 \\ 20.10 & 25 & 5 & 60 & 32 & 27 & 30 & 54 & 30 \\ 27.10 & 32 & 5 & 100 & 53 & 39 \dagger & 44 & 66 & 43 \dagger \\ 3.11 & 38 & 4 & 122 & 63 & 35 & 50 & 60 & 39 \\ 10.11 & 45 & 3 & 110 & 53 & 33 & 43 & 57 & 36 \\ 24.11 & 69 & 3 & 110 & 50 & 30 & 40 \dagger & 58 \dagger & 33 \dagger\end{array}$

In the second series the same general tendencies in growth are shown over corresponding periods of time, the greatest difference being the better growth of the diatoms supplied with most rubidium, viz. culture $4 \mathrm{a}$ supplied with $21 \gamma$ rubidium per c.c. of culture medium (Table V).

\footnotetext{
* Empty frustrules numerous. Culture obviously dying off.

$\leftarrow$ Frustrules healthy, but small in size.

$\ddagger$ Culture found overturned.
} 


\section{TABLE V.}

To show the result of correlating numbers giving increase in growth and the available potassium or rubidium per diatom in gram atoms.

\section{The Potassium-containing Cultures.}

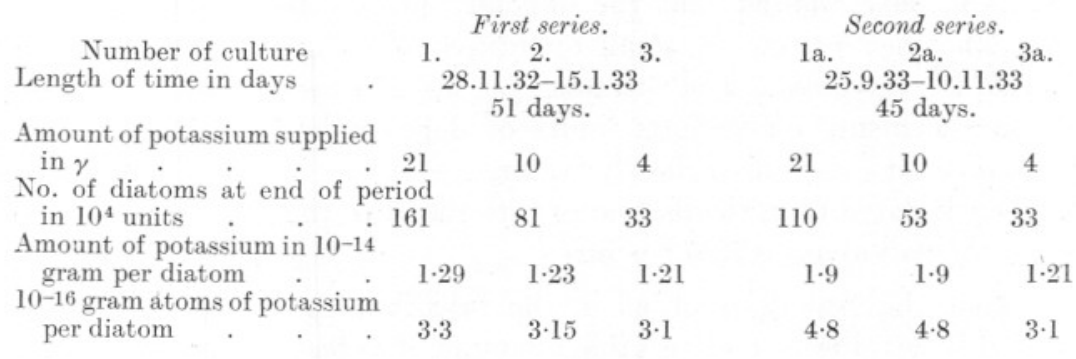

TABLE VI.

The Rubidium-containing Cultures.

\begin{tabular}{|c|c|c|c|c|c|c|}
\hline \multirow{2}{*}{$\begin{array}{l}\quad \text { Number of culture } \\
\text { Length of time in days } \\
\text { Amount of potassium supplied } \\
\text { in } \gamma\end{array}$} & \multicolumn{3}{|c|}{$\begin{array}{l}\text { First series. } \\
2 . \\
28.11 .32-15.1 .33 \\
\text { 51 days. }\end{array}$} & \multicolumn{3}{|c|}{$\begin{array}{l}\text { Second series. } \\
\text { la. } 2 \mathrm{a} . \quad 3 \mathrm{a} . \\
25.9 .33-10.11 .33 \\
45 \text { days. }\end{array}$} \\
\hline & 21 & 10 & 4 & 21 & 10 & 4 \\
\hline No. of diatoms at end of period & & & & & & \\
\hline $\begin{array}{l}\text { in } 10^{4} \text { units } \\
\text { Amount of rubidium in } 10^{-14}\end{array}$ & 29 & 52 & 42 & 43 & 57 & 36 \\
\hline $\begin{array}{l}\text { gram per diatom } \\
10^{-16} \text { gram atom of rubidium }\end{array}$ & $7 \cdot 2$ & 1.92 & 0.91 & $4 \cdot 9$ & $1 \cdot 75$ & $0 \cdot 11$ \\
\hline per diatom & 8.5 & $2 \cdot 25$ & $1 \cdot 07$ & $5 \cdot 76$ & $2 \cdot 06$ & $1 \cdot 3$ \\
\hline
\end{tabular}

Tables V and VI show the results of correlating the figures of increase in numbers, with the amounts of available potassium or rubidium present in the two series after periods of 51 days and 45 days in the first and second series respectively. During these times growth had been fairly regular and steady in the two sets of experiments.

From these figures it will be seen that the individual diatom requirement is approximately $1 \cdot 3 \times 10^{-14} \mathrm{gr}$. K. per unit. Using this figure it is therefore possible to estimate the amount of undetectable potassium present in the so-called potassium-free artificial medium. Reference to Table II shows that this artificial medium gives an increase of growth, reaching 6 diatoms per $0 \cdot 1 \mathrm{~mm},{ }^{3}$ of culture medium. The potassium impurity must therefore approximate 0.78 micrograms per litre of solution.

It is also interesting to compare the potassium requirement of the diatom with the corresponding phosphorus need. Atkins has shown (4) that in fresh cultures, $1.12 \mathrm{mg}$. phosphorus as $\mathrm{P}_{2} \mathrm{O}_{5}$ will produce $1 \times 10^{9}$ 
diatoms. The phosphorus per diatom in gram atom obtained from this figure is $15 \cdot 8 \times 10^{-15}$ gram atoms as compared with $3 \cdot 3 \times 10^{-16}$ gram atoms potassium per diatom. The phosphorus-potassium ratio is therefore approximately 50 .

\section{Conclusions.}

1. It is fully realised that the difficulty in detecting potassium and rubidium when present in small quantities and together with salts of sodium, is very great. The spectroscopic method used for the detection of these elements reached its limits of delicacy between 21 and $10 \gamma$ potassium per c.c. in artificial sea-water.

It is calculated from the diatom growth recorded that the undetectable potassium was about $0.78 \gamma$ per litre.

2. That the growth recorded in the rubidium-containing cultures 4 , 5 and 6 is not due to undetectable amounts of potassium present, as an impurity in the rubidium sulphate is fairly obvious when it is considered that the actual amounts of rubidium provided were 21,10 and $4 \gamma$ per c.c. of culture medium respectively. In view of the tested standard of purity of the chemicals used, it follows that any trace of potassium introduced, must of necessity be very small. Yet in the experiments 3 and $3 \mathrm{a}$ which received $4 \gamma$ potassium per c.c. growth was no better than that of cultures 6 and $6 \mathrm{a}$ which received a similar amount of rubidium.

3. It may be concluded that when rubidium is supplied in small amounts (see cultures 6 and $6 \mathrm{a}$ ) this element equals in efficiency similar amounts of potassium (see cultures 3 and $3 \mathrm{a}$ ). In larger amounts, e.g. $21 \gamma$ rubidium per c.c., rubidium would appear to be harmful. The diatoms in the rubidium-containing cultures seem to be limited to an increase of seven to eleven times their original number, so that even when the rubidium is not harmful the total replacement of potassium seems impossible.

4. It would seem that $3 \cdot 1 \times 10^{-16}$ gram atoms of potassium per diatom is approaching the limiting value of this element for the continued growth of Nitzschia closterium. For rubidium the corresponding figure is about $1 \cdot 1-1 \cdot 3 \times 10^{-16}$ gram atoms of rubidium per diatom.

5. Comparing the phosphorus requirement of Nitzschia closterium with that of its potassium need, the ratio of phosphorus-potassium is approximately 50 .

I am greatly indebted to Dr. E. J. Allen for laboratory facilities and to Dr. W. R. G. Atkins for suggesting and directing the subject of the research and for his help and encouragement throughout the experiments. 


\section{REFERENCES.}

1. Allen, E. J. 1914. On the culture of the plankton diatom Thalassiosira gravida Cleve, in artificial sea-water. Journ. Mar. Biol. Assoc., N.S., Vol. X, pp. 417-439.

2. 1919. A contribution to the quantitative study of plankton. Ibid., N.S., Vol. XII, pp. 1-8.

3. Allen, E. J., and Nelson, E. W. 1907. On the artificial culture of marine plankton organisms. Ibid., N.S., Vol. VIII, pp. 421-474.

4. Аткіns, W. R. G. 1923. The phosphate content of fresh and salt water in its relationship to the growth of the algal plankton. Ibid., N.S., Vol. XIII, pp. 119-150.

5. Atrins, W. R. G., and Werner, E. A. 1912. The dynamic isomerism of ammonium thiocyanate and thiocarbamide. Trans. Chem. Soc., Vol. 101, pp. 1167-1178.

6. - The influence of certain salts on the dynamic isomerism of ammonium thiocyanate and thiocarbamide. Ibid., pp. 1982-1991.

7. BRooks, S. C. 1932. The rate of penetration of rubidium into living cells of Valonia and its relation to apparent ionic radii. Journ. Cell. and Comp. Physiol., Vol. 2, pp. 223-231.

8. Cameron, C. A. 1867. Substitution of rubidium for potassium in plants. Sci. Proc. Roy. Dub. Soc., Vol. 5, pp. 85-89.

9. — 1879. Preliminary notes on the absorption of selenium by plants. Sci. Proc. Roy. Dub. Soc., N.S., Vol. 2, pp. 231-233.

10. Gooch, F. A., and Phinney, J. I. 1892. Quantitative determination of rubidium by the spectroscope. Amer. Journ. Sci., Vol. XLIV, pp. 392-400.

11. Harshberger, J. W. 1917. Mycology and plant pathology.

12. Hodgetts, W. J. 1922. A study of some factors controlling periodicity of fresh water algæ in nature. New. Phy., Vol. XX.

13. Јоsт, L. 1913. Varlesungen Ürbe pflanzers physiologie.

14. Macallum, A. B. On the distribution of potassium in animal and vegetable cells. Journ. Physiol., Vol. 32, pp. 95-126.

15. Pfeffer, W. 1905. Physiology of plants. Vol. 1, p. 411, pp. 430 and 429 .

16. — 1905. Physiology of plants. Vol. 3, p. 350.

17. Stanbury, F. A. 1931. The effect of light of different intensities, reduced selectively and non-selectively, upon the rates of growth of Nitzschia closterium. Journ. Mar. Biol. Assoc., N.S., Vol. XVII, pp. 633-654. 
